\title{
EPIDEMIOLOGICAL AND CLINICAL DATA OF PEDIATRIC STREPTOCOCCAL INFECTIONS OF ELBASANI DISTRICT, ALBANIA
}

\author{
E. Laho, G. Kuli-Lito \\ Regional Pediatric Hospital, Elbasan, Albania
}

Background and aims: Streptococcus pyogenes (group A Streptococcus) is one of the most important pathogens encountered in clinical practice. An understanding of the diverse nature of infectious disease problems attributable to this organism is an important cornerstone of pediatric medicine.

The aim of the study was to estimate the burden of streptococcal infections throughout of their incidence and prevalence, to estimate the short and long term complications.

Method: Prospective collection of clinical and microbiological data from 2004 until 2008 of 173 children admitted to the pediatric ward with bacteriologicaly proved pharyngotonsillitis of Strep. group A in the hospital of the city of Elbasan.

Results: Males and females are equally affected $59 \%$ and $41 \%$ respectively but the mean age for both of them is equal, $5.7 \mathrm{yrs}( \pm 0.2 \mathrm{SD})$. Most of cases, $34.5 \%$, belong to age group 3-5 yrs old followed by age group 6-8 yrs old with $22.2 \%$ of cases. The prevalence of streptococcal pharyngitis was found $22 \%$ and its incidence $37,2 \%$ per year. The serious long-term complications were FR (Rheumatic Fever) in 4 cases $(2,3 \%)$ and Glomerulonephritis in $3(1,7 \%)$ children. The most effective treatment is achieved by the antibiotics such as penicillin and cephalosporin

Conclusions: Streptococcal infections occur frequently during the autumn and winter.

The most affected is age group 3-5 yrs old and early treatment reduces long-term complications. 